\title{
The Ever Challenging Environment of Producing Knowledgeable and Skillful Graduates: Changing the Culture of Higher Education of Institutions in Teaching and Learning Approaches
}

\author{
Sabarudin Zakaria \\ Faculty of Management, Multimedia University, Malaysia
}

Copyright $\subseteq 2017$ by authors, all rights reserved. Authors agree that this article remains permanently open access under the terms of the Creative Commons Attribution License 4.0 International License

\begin{abstract}
The education system of modern society can be understood as an institution whose functions include its capacity to reproduce its host society, both economically and culturally [1]. Higher institution of learning is no more seen as a place of mass production of graduates willingly believes that they are now ready to perform their duties. The newly developing higher education system has expanded to prepare a new workforce which can assist in the economic growth of the nation and thus the outputs that fulfill this must be able to perform to the needs of the industry. What the industry wants is students too show that they have entered and translated into what they have learned practically. Thus, today educators and academicians has to aggressively re-look and change the teaching and learning approaches and environment in order to make the teaching and learning process more effective and relevant. It is not sufficient by merely changing the content of the curriculum but it is more than that. This paper analyses the feedback of students on the current method of teaching and learning in comparison to the contemporary approach of teaching such as active learning, outcome-based learning and problem-based learning. The study will also explore the process of integrating these active learning strategies into traditional lecture-based courses and also intend to underscore the motivation and incentives required for bringing about changes, and the support needed for sustaining and disseminating active learning approaches among the educators.
\end{abstract}

Keywords Teaching, Learning, Students, Educators and Change

\section{Introduction}

Good teaching is about substance and treating students as consumers of knowledge. Knowledge refers to doing your best to be well verse on your field, reading sources, inside and outside of your areas of expertise as well as being at the leading edge as often as possible [2]. Our new world is all in favour of learners and learning but somewhat circumspect about teachers and teaching [3]. There are still some questions on the debate of effective teaching need to be answered earnestly, as the matter has become interestingly discussed. One of the teaching methods that necessitates students' activities, problem-solving and cooperative learning that permit a degree of students' control over learning and can thus accommodate individual differences in their preferred ways of reaching understanding[4]. Thus institutions of higher learning are facing new challenges in their efforts to improve the quality of education. Teachers in higher education must focus on customers (i.e. students) needs in order to be successful. Qualified teachers must know how to organize and teach lessons in ways that assure students learn these subjects despite their diversity[5].

The higher tuition fees are spurring interest in the study of quality assurance in higher education that motivates the need to focus on improving the quality of actions as well as interactions in teaching and learning process. This includes improvement in the areas of teaching methods, subject designs and objectives, course notes and books, resources, staff-student interactions, assessments and subject evaluations [6]. Learning is crucial in knowledge management as it provides an avenue for the organization to infuse new knowledge [7]. The quintessential of quality teaching is the ability of lecturers or educators delivering lessons effectively and competently. A competent lecturer is the culmination of having the appropriate qualifications, commitment and passion for teaching. [8] Defined teaching as a student's education meeting the student's expectations. The implication of this definition to teachers is they need to thoroughly understand the content of their teaching [9]. 
Teaching as a method of imparting knowledge from research has shown that traditional lecturers predominates university classrooms [10].

Given these observations the general objectives of the study is to identify student's view and perception of teaching whether the profound effectiveness of learning is based on teacher-centered or student-centered. Second to justify that there is a need to change the approach of learning which is student-centered such as problem-based learning or active learning. The outcomes of the findings will induce the university learning to be student centered vis a vis transforming the learning culture and approach. Hoping learning will be focused on activity, discovery and independence [11]. Questionnaires will be distributed to students in a local university which comprises of various disciplines. The questionnaire consists of statements representing agreement or disagreement to gauge the teaching philosophical inventory of the respondents which will be significant to this study.

\section{Literature Review}

Higher institution of learning has continued to play an important role in the economy as a producer of human capital and as a center for research and development. However, in thriving to reach this role is not an easy path, the bottom line issue to be addressed is whether it has met the necessary accreditation and quality assurance to produce quality human capital and excellent center for development. In current competitive business world, it is visible that education should be beneficial to both students and their future employers. Since students are potential executives with prospect to have a successful career in their respective appointment, universities are accountable to offer effective learning experience to accommodate these needs.

Traditional educational practices centres on "inputs" [12]. Generally the system exposed students to a segment of curriculum over a time frame. At the end of the module, an examination is usually given, and grades are assigned regardless of whether all students have achieved mastery of the material learned. This perspective needs to be changed where the "outputs" is not just getting good results but it is important they can meet the needs of the potential employers in demonstrating their competencies. New role for educators today is to meet the challenges of the new educational approach, lecturer's roles have been reconceptualised [13]. Lecturers need to be supported to make the paradigm shift that is required to understand new approach in teaching and to understand the necessary competences that are essential for fulfilling the expanded roles of the educator.

One of the most important findings of educational research is that the meaning of orientation to learning is positively associated with students' perception of the learning environment. [14] Reported positive relationships between teaching characteristics, meaning orientation to learning and positive attitude to studying. Most Higher Education Institutions (HEIs) agree that lecturers have the greatest impact on students' changes in their aspirations, values, attitudes, beliefs and actions [15]. However, the interaction in class today is more on one-way communication, where teacher is doing all the active talking, while students are listening to the lecture. Students are afraid to voice out their opinion. As a result, students are being passive, thus lacking of some skills such as communicative skills, critical thinking, and decision making.

Dr. Parmjit Singh of Asia Pacific Institute of Information Technology [16](APIIT) in 2004 showed that three main complaints received regarding the local graduates include lack of creativity, lack of initiatives, and poor communication skills [17]. Due to these problems, graduates are unable to perform well in their job and hard to get jobs desired. Therefore, this also leads to the increment of number of unemployed graduates. With more demanding future employers, educators are moving one step ahead by changing their way of teaching. Therefore, the near future education is facing the challenge of preparing students especially undergraduate students with the necessary knowledge, skills, and disposition to meet increasingly complex needs of the environment. However, in order to achieve degree with quality which is consistent with practical requirement, universities are required to have an increase interest in developing an effective teaching. In addition with the establishment of Ministry of Higher education (MOHE) in 2004, initiated by the government is to make Malaysia a centre of educational excellence in producing skilled human workforce [18]. Such initiative and interest shows that the government's effort on quality needs to be improved in Malaysian education system to stir the Malaysian education industry inclusive of government, academicians and students.

The most important and essential initiative that should be done aggressively today is the adopting of student-centered learning at the higher institutions of higher learning. Student-Centered Learning represents both a mind-set and a culture within a given higher education institution and is a learning approach which is broadly related to, and supported by, constructivist theories of learning [19]. It is characterized by innovative methods of teaching which aim to promote learning in communication with teachers and other learners and which take students seriously as active participants in their own learning, fostering transferable skills such as problem-solving, critical thinking and reflective thinking. This learning model places the student (learner) in the center of the learning process. The instructor provides students with opportunities to learn independently and from one another and coaches those in the skills they need to do so effectively [20]. The approach includes such techniques as substituting active learning experiences for lectures, assigning open-ended problems and problems requiring critical or 
creative thinking that cannot be solved by following text examples, involving students in simulations and role plays, and using self-paced and/or cooperative (team-based) learning.

Today and in the coming years, teaching will be more digitalized and sophisticated with the expansion of technology. Technology has the power to free people from those limitations, to make education far more portable, flexible, and personal; to foster initiative and individual responsibility; to restore the treasure-hunt excitement to the process of learning. Technology offers another potential benefit as well: the Internet can make education far, far more accessible, so knowledge and opportunity can be more broadly and equitably shared [21](Khan, 2012). However, it is imperative that it is not only technology is important, but also the learning methodologies utilized to employ the technology [22]. For example in distance education the successful use of the technology involves virtual classes that are very different from face-to-face class.

\section{Research Methodology}

A set of statements consisting of four sections with each section comprises of five statements are adopted with modification [23] (Hussain Othman., 2011). These statements represent teaching philosophical perspective inventory on students learning references whether they are more towards teacher-centered or student-centered. The statements are divided into four parts A, B, C and D. Part A and $\mathrm{B}$ divulging how is the learning teacher centered is while $\mathrm{C}$ and $\mathrm{D}$ deals with the need to experience learning through students' needs and desire i.e. student centered. This questionnaire is distributed to 200 students in a renowned private higher education institution in Selangor, Malaysia. A total of 200 questionnaires are distributed and all of them are returned. The students are divided into nine focus groups which represent several disciplines representing management, accounting, finance and marketing.

\section{Findings}

Generally the students' views that the role of teachers input in teaching is still important and relevant. Especially concerning the early part of their learning. The total mean score of 35/50 for both Part A (Table 1) and B (Table 2) illustrated that teacher centered learning is still needed for the following fundamentals as shown in table A and B. For example theories and general topics should be taught before going into the application parts. In addition, common basic subject should be thoroughly taught which also includes general academic disciplines. The role of teachers is also to train the mind and promote reasoning as to build critical thinking and experience.
Table 1. A-Teachers- centered

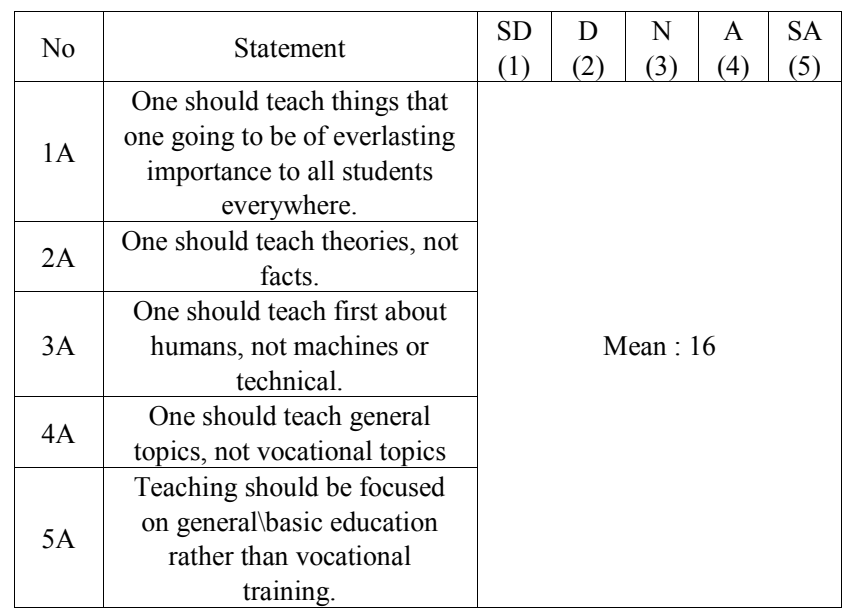

SD-Strongly Agree, D-Disagree, N-Neutral, A-Agree, SA-Strongly Agree

Table 2. B - Teachers- centered

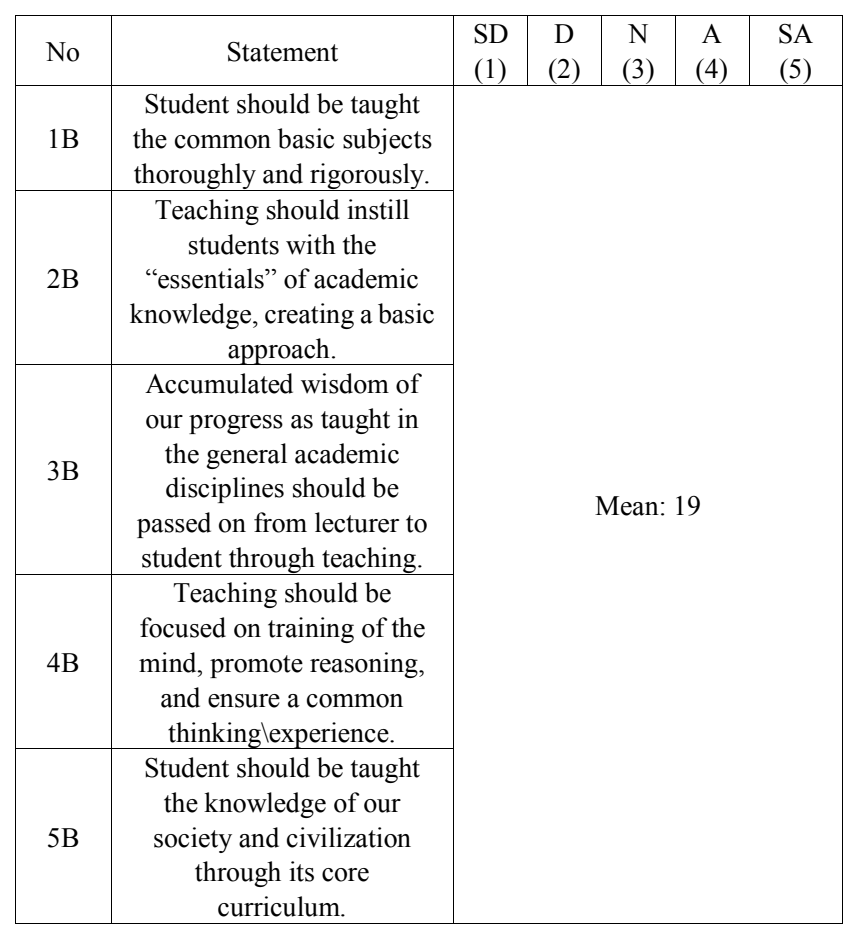

SD-Strongly Agree, D-Disagree, N-Neutral, A-Agree, SA-Strongly Agree

On the contrary the students should equally play their role in the learning process. The statement analysis demonstrates the score of $39 / 50$ or $78 \%$ that learning now is no more a one way traffic where the teacher determines and dictates the learning. Students want to play an active role in their learning as indicated by the degree of agreement towards the statement on student-centered learning. They want actual learning through hands-on assignment, be creative in problem solving, learning in group which include cooperation and coordination. Action learning should be in the menu and they also want to be involved in assessment and evaluation. As for the curriculum it should be culturally reflected on the society globally and discussing controversial issues that affect them. Learning is not just academically 
focused but should be applicable and can bring changes to the society both the present and the future. Instead of students been bombarded with theories or concept, the learning must involve active participation from the students.

Table 3. C - Student-Centered

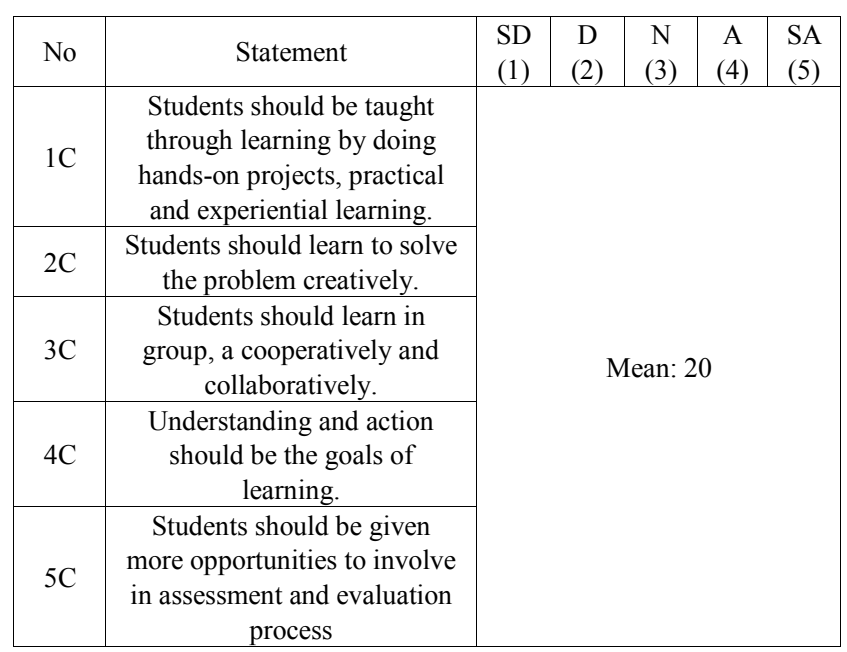

SD-Strongly Agree, D-Disagree, N-Neutral, A-Agree, SA-Strongly Agree

Table 4. D - Student-Centered

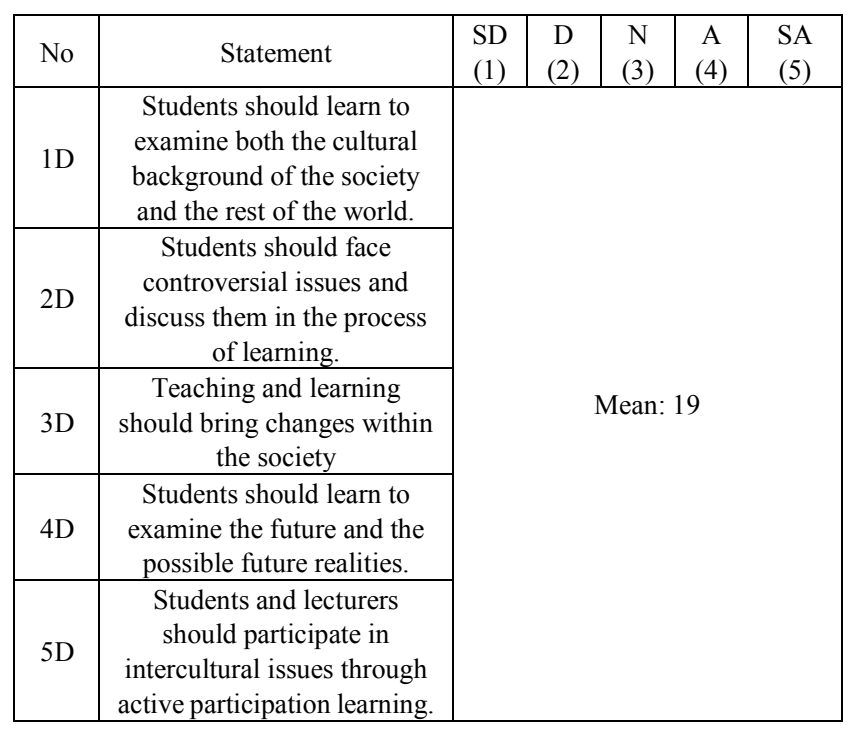

SD-Strongly Agree, D-Disagree, N-Neutral, A-Agree, SA-Strongly Agree

\section{Discussion}

Briefly from the findings it can be deduced that teachers still play an important catalyst in teaching and creating learning among students. However, as the new generation $\mathrm{Y}$ and $\mathrm{Z}$ so called, student as the main stakeholder demand more than that. They want to be heard and participate in inculcating better understanding in their learning. Better yet, they consider of more ways in engaging them even if only for brief periods of time-in talking or writing about the ideas presented in the lecture. [24] While lecturing is an important aspect of university instruction; it is not necessarily the only or best way of engaging students in the ideas and information we're presenting. Learning now has gone through many changes with more interactive approach and induces more two ways communication. Active learning, action learning, experiential learning, problem-based learning, blended learning or flip learning or whatever name been called on these new learning approaches which have been introduced with the learner as the main focusses. This entire active learning environment, teachers facilitate rather than dictate the students' learning [25].

All this new concept of learning is simply having students engaged in some activities that force them to think about and comment on the information presented. So they won't simply be listening, but will be developing skills in handling concepts in related disciplines. They will analyze, synthesize, and evaluate information in discussion with other students, through asking questions, or through writing. In short, students will be engaged in activities that force them to reflect upon ideas and upon how they are using those ideas.

In Malaysia a number of higher institutions have considered innovations in their approaches to teaching. Transition of approaches from traditional to new innovative approaches is being implemented in many higher institutions. In addition to the advancement of technology, computers and LCD are taking place and the settings of classes are also changing. With these changes, educators are moving one step ahead by changing their way of teaching. Digital learning, online learning, web tools are some of the innovation explored by higher education of learning in delivering efficient and effective teaching as well as learning.

\section{Conclusions}

Basave argued that to impose a certain education system without taking into account the diversity and the aspirations of those for whom it is designed, is to go against the nucleus of human beings, and their intellectual and cultural aspects [26](Bridger, 2007). Thus from the findings it is clearly defined by the students that they need a new paradigm and culture in the way they want to learn. The role of a teacher as the finding shows is still needed in departing the fundamentals of the subject they learned. However, the learning culture that was in place all these years was almost exclusively teacher led, there was passivity among the students, a practice of routine learning was rampant, with little reliance on creativity, initiative and independency. Looking at Malaysia and the world at large, it has undergone rapid socio-political and economic change. This has direct implications for education. To meet these new needs, there is an urgent need to improve curriculum and teaching and learning in the higher institutions of learning so that it will become more responsive and action oriented vis a vis students centered. This approach if properly implemented can lead to the increase in motivation to learn, greater 
retention of knowledge, deeper understanding, and more positive attitudes towards the subject being taught [27] (Froyd \& Simpson, 2008). Furthermore, the changing demographics of the students' population and the more consumer/client-centred culture in today's society have provided a climate where the use of student-centered learning is thriving [28](O'Neill, \& McMohan, 2005).

\section{REFERENCES}

[1] Barnet, R, (1994), The Idea of Higher Education, The Society for Research into Higher education \& Open University Press.

[2] Leblanc, R (1998). Good teaching: The top ten requirements, The Teaching Professor, York University, Ontario.

[3] Badley, G (1999), Improving teaching in British higher education, Quality Assurance in Education, Volume $7 \cdot$ Number 1 .

[4] Van Dijk, L.A. \& Jochems, W.M. (2002), Changing a Traditional Lecturing Approach into an Interactive Approach: Effects of Interrupting the Monologue in Lectures, International; Journal Engineer Education., Vol. 18, No. 3, pp. $275-284$.

[5] Thompson, S, Greer, G.G. and Greer, B.B, (2004) Highly Qualified for Successful Teaching: Characteristics Every Teacher Should Possess, The University of Memphis

[6] Lee F.T \& Yeap, B.H (2005) Application of Effective Teaching and Learning Methods in Engineering Education, Monash University Malaysia

[7] Gan, G.G., Ryan, C. and Gururajan, R,(2000), The Effects of Culture on Knowledge Management Practice: A Qualitative Case Study of MSC Status Companies, Kajian Malaysia, Vol. XXIV, No. 1 \& 2

[8] Brocato, R. and Protocki, K. (1996). We care about students...one student at a time. Journal for Quality \& Participation, volume 19, page $74-79$

[9] Adediwura, A.A and Tayo, B (2007), Perception of teachers' knowledge, attitude and teaching skills as predictor of academic performance in Nigerian secondary schools, Educational Research and Review, Vol. 2 (7), pp. 165-171.

[10] Van Dijk, L.A. \& Jochems, W.M. (2002), Changing a Traditional Lecturing Approach into an Interactive Approach: Effects of Interrupting the Monologue in Lectures, International; Journal Engineer Education., Vol. 18, No. 3, pp. $275-284$

[11] Carlile, O., and Jordan, A., (2005). It works in practice but will it work in theory? The theoretical underpinnings of pedagogy. In S. Moore, G. O'Neill, and B. McMullin (Eds.), Emerging Issues in the Practice of University Learning and Teaching. Dublin: AISHE

[12] McNeir, G., (1993). Outcome-Based Education, ERIC Digest.

[13] Steinberg, H., (2006). Facilitating Outcome Based Learning \& Teaching, South African Institute for Distance Education, South Africa.
[14] Mayya, S., \& Roff, S., (2004). Students' perceptions of the educational environment: a comparison of academic achievers and underachievers at Kasturba Medical College, India. Educ. Health. 17(3):280 -91.

[15] Chepchieng, M.C., Mbugua, S.N., \& Kariuki, M.W., (2006). University students' perception of lecturer-student relationships: a comparative study of Public and Private Universities in Kenya, Educational Research and Reviews, Vol. 1 (3), pp. 80-84.

[16] APIIT

[17] Hii, C., (2007). Soft Skills Essential for Success in Today's Workplace. Accessed at http://thestar. com.my/news/story.as p? file $=/ 200 / 9 / 23 /$ focus $/ 18887876 \&$ sec $=$ focus

[18] Rassiah, P., Seng YC., \& Jayabalan, J., (2008), The relationship between student satisfaction and academic performance in the private higher education institutions in Malaysia, $8^{\text {th }}$ Annual SEAAIR Conference, 4-6 November, Surabaya, Indonesia.

[19] Attard, A., Di Iorio. E., Geven. K \& Santa, R.,(2010). Student-Centred Learning - Toolkit for Students, Staff and higher education institutions, Education and Culture, Brussels.

[20] Froyd, J., \& Simpson, N., (2008). Student-Centred Learning-Addressing Faculty Questions about Studentcentred learning, Texas A\& M University.

[21] Khan, S (2012). Teaching for the Millennium, Mckinsey and Company, Accessed at http://www.mckinsey.com /industries/public-sector/ our-insights/teaching-for-the-newmillennium, On $22^{\text {nd }}$ November 2016.

[22] Rogers, D.L, (1999), A Paradigm Shift: integration for higher education in the New Millennium, Educational Technology Review, www.learntechlib.org/d/8058.

[23] Hussain Othman., (2011). Problem-Based Learning Workshop for Trainers, Faculty of Science, Technology and Human Development, University Tun Hussein Onn, Malaysia.

[24] CTL, (1993), Active Learning: Getting Students to Work and Think in the Classroom, Stanford University Newsletter on Teaching, Vol. 5 , No. 1.

[25] TA consultants. (2008). Active Learning, Accessed from http://cetl.ucdavis.edu/wp-content/uploads/

2010/10/Active-learning.pdf, on $4^{\text {th }}$ March 2013, Center for Excellence in Teaching and Learning, University of California.

[26] Bridger, J., (2007). From passive to active learners: The "lived experience" of nurses in a specialist nephrology nursing education programme, Journal of Workplace Learning, Vol. 19, No. 2.

[27] Froyd, J., \& Simpson, N., (2008). Student-Centred Learning-Addressing Faculty Questions about Studentcentred learning, Texas A\& $M$ University.

[28] O’Neill, G., \& McMohan, T., (2005), Student-Centered Learning: What does it mean for students and lecturers? Accessed at: http://www. Aishe.org/readings/200-1/oneill-mc mahon-Tues $19^{\text {th }}$ Oct html\#XCarlile2005 on $4^{\text {th }}$ March 2013, University College Düblin. 